\title{
Awarua and the dragon: storytelling as a stimulus for early childhood teaching and learning in two cultural contexts
}

\section{Lisa Gabriella Terreni, Judith Loveridge, Rachel Denee \& Jing Zhou}

To cite this article: Lisa Gabriella Terreni, Judith Loveridge, Rachel Denee \& Jing Zhou (2021): Awarua and the dragon: storytelling as a stimulus for early childhood teaching and learning in two cultural contexts, International Journal of Early Years Education, DOI: 10.1080/09669760.2021.1894100

To link to this article: https://doi.org/10.1080/09669760.2021.1894100

Published online: 03 Mar 2021.

Submit your article to this journal $\sqsubset$

山 Article views: 221

à

View related articles $\sqsubset$

View Crossmark data $₫$ 


\title{
Awarua and the dragon: storytelling as a stimulus for early childhood teaching and learning in two cultural contexts
}

\author{
Lisa Gabriella Terreni, Judith Loveridge, Rachel Denee (D) and Jing Zhou (D)
}

Education, Victoria University of Wellington, Wellington, New Zealand

\begin{abstract}
In this article, we examine how teachers in two kindergartens, one in New Zealand and one in China, used the stimulus of a fictional story combining mythical creatures from Māori and Chinese culture to enhance young children's sense of place and cultural identity. Sociocultural understandings about the role of collaboration and cultural tools in meaning-making informed the research design. Teachers' documentation about the children's learning throughout the project was analysed and focus group interviews were conducted with teachers and parents. Findings demonstrated that story-telling provided an effective stimulus for children's learning using a range of multi-literacies. It was also helpful for exploring and connecting children, teachers and families with significant aspects of the cultural backgrounds of the children. The research also revealed that teachers engaged in intentional teaching practices to achieve these outcomes but experienced challenges (pedagogical knots) as they used the story. Nonetheless, we argue that the use of storytelling can be a powerful tool for fostering greater understanding for children, teachers and families of their own and others' cultures.
\end{abstract}

\section{ARTICLE HISTORY}

Received 30 January 2020

Accepted 18 December 2020

\section{KEYWORDS}

Storytelling; early childhood; culture; literacies; intentional

\section{Introduction}

In both New Zealand and China, the role of the early childhood teacher has often been debated and contested (Edwards and Cutter-Mackenzie 2011; Murray 2015). An examination of shifting early childhood education (ECE) pedagogical approaches, particularly in the West, has seen the role of the teacher described in opposing stances: where teachers direct and instruct the passive child or where they stand back without interfering with a child's natural development, to one where teachers play an active and intentional role as co-constructor of learning (Murray 2015). In New Zealand, a progressive approach to early childhood education emerged after World War 2 (May 1997) and play-based learning (White et al. 2008) and relational pedagogy (Peters 2009) are now dominant pedagogical approaches. ECE in China now 'reflects the hybrid of traditional, communist and Western cultures' (Zhu and Zhang 2018, 1188), and since the 1980s there has been a series of early childhood educational reforms, referred to as 'the coming spring for ECE in China' (Liu and Pan 2013, 141). Ideas have been borrowed from different 
Western pedagogical theories (Tobin, Hsueh, and Karasawa 2009) and an ideology that considers children and educational values in the curriculum has been a driving force away from a traditional directive approach. Many teachers are recognising that they 'need to make authentic connections between learning tasks they plan and the activities which children themselves initiate' (Zhu and Zhang 2018, 1184), and that children's interests can be used as important catalysts for teaching and learning.

In an increasingly globalised world many nations like New Zealand and China have experienced proliferating ethnic and cultural diversity among their populations. The task of supporting children to create a positive sense of their own cultural identity starts in early childhood, where children often encounter others with diverse cultural and ethnic identities for the first time. Terreni et al. (2018) suggest that stories (particularly myths and legends), which contribute to culture and national identity, may help young children begin to know 'who they are and where they are from' (9). When teachers use stories to encourage explorations of identity, it can open up exciting learning opportunities for children to gain new knowledge. Black (1999) argues that 'because stories and traditions touch the heart as well as the mind, they change the ways that children understand and respond to people of another culture' (333). Similarly, Kelly-Ware and Daly (2019) highlight the potential for books and stories to be both mirrors, reflecting children's lives, and windows into other people's lives.

In this article, we explore a curriculum innovation that aimed to connect two early childhood centres through the use of a fictitious story Awarua and the Dragon (see Terreni 2016 http://olivepress.co.nz/Awarua_and_the_dragon.html), which encouraged the practice of providing children with multi-literacy experiences (The New London Group 1996), to explore children's and families' senses of identity and place. Multi-literacies, which include the literacies of visual art, dance, drama, music and movement, to name a few, are powerful for making visible the inter-relationship of different modes of meaning' (The New London Group 1996, 78). The fictional story was created using a Taniwha from Māori mythology and a dragon from Chinese mythology who meet each other.

In this research project sociocultural theory informed the use of both the pedagogical stimulus (i.e. the shared story across two different cultural contexts) and the research design. Sociocultural theory conceptualises culture as multi-dimensional and in flux (Henning and Kirova 2012), and it provides useful tools for exploring evolving culturally diverse representations of identity and sense of place. It suggests that as people participate in the activities and processes of their communities, they learn how to be members of their communities (Rogoff 2003; Stetsenko 2005).

Sociocultural theory recognises that children's thinking is a collaborative process that is contextually located, mediated by tools and artefacts (Robins 2005). By investigating the story of Awarua and the Dragon (a cultural artefact), the children, and their families and teachers, were afforded opportunities to explore their sense of place and their own cultural identity. To do this they used the learning tools and other artefacts available to them in the kindergartens. As will become evident, at both the group and individual level, the sense of cultural identity and sense of place of each kindergarten community was transformed through the investigation of the story. Through the children's own interpretation of the story and the emergence of new stories and the resulting artwork, 
songs, constructions and drama that the children produced, the story also became transformed.

The research investigated how story telling can enhance young children's sense of place and cultural identity (their own as well as that of others), through examining the learning opportunities generated by the shared story telling. It also sought to examine if story telling can foster greater understanding for teachers and the community of the cultural backgrounds of children attending the centres in both New Zealand and China.

\section{Methodology and methods}

The research design for this project was a collaborative exploratory case study with two sites of analysis conducted over the course of a year. Case study research was chosen because it is a particularly appropriate approach where an in-depth understanding of a phenomenon is required (Yin 2018). The two case studies in different cultural contexts were also chosen to create a cultural exchange between the two early childhood settings. The two centres were invited to participate because of existing professional relationships between the research team members (the names of the two kindergartens are anonymised in this article). Ethical approval was gained from Victoria University of Wellington's University Ethics Committee. All participants gave informed consent for their participation in the project and parents gave consent for the use of the documentation associated with their children and the project.

\section{Background}

Karehana Bay Kindergarten, the New Zealand centre involved in the study, is situated in a small beachside village and services a predominantly middle class, well-resourced community. Forty children, aged 2-5 years-old, attend per day. The teaching team consisted of one head teacher and four teachers. The teaching philosophy at Karehana Bay Kindergarten supports children learning through their play and having agency in leading their own learning. Karehana Bay Kindergarten is committed to bicultural practice by respecting Māori as tangata whenua (the indigenous people of New Zealand) and through incorporating environmental place-based education (Penitito 2009). These aspects of the philosophy have resulted in a long-running nature education programme involving weekly trips to the local bush and beach, with an aspiration of connecting to local Māori history and stories through the natural environment. Consequently, the teaching team and community were enthusiastic about the invitation to participate in this project because they felt that it connected to their philosophy, aspirations and programme.

Lotus Kindergarten, the Chinese centre involved in the study, is situated in the extremely large urban area of Beijing. It also services a predominantly middle class, wellresourced community. The Kindergarten has approximately one hundred and eighty children, aged from 3 to 6 years, attending and a team of more than thirty staff members. Their daily schedule involves segments of free play and segments of structured group learning time, with two hours spent outdoors each day.

The teaching approach at Lotus Kindergarten focusses on children as competent and active learners and communicators. The teachers have been involved in professional learning over the past years directed at making a shift from the Chinese traditional 
approach (which was heavily teacher-directed), towards a more holistic approach which values free play, and the empowerment of children through reciprocal and responsive relationships. The invitation to participate in this project offered a timely opportunity for the teaching team to delve further into an exploration of their pedagogy and practice. Although the initial proposal was for one classroom to connect with Karehana Bay Kindergarten, it was so enthusiastically received by many of the Lotus teachers that six different classrooms chose to engage with the project.

\section{Data collection and analysis}

A range of data were generated in each kindergarten. For example, teachers in each context collated a selection of the documentation of children's learning. Learning Stories (Carr and Lee 2012), videos and photos were used to capture the stories, songs, dance, drama, constructions and artwork that children created. Examples of these were sometimes shared between the two kindergartens using e-mails and Skype. The documentation by the teachers and examples of artefacts created by children were helpful for investigating 'layers of experience that cannot easily be put into words' (Bagnoli 2009, 548) and for revealing how the children's work developed and was transformed over time.

The researchers conducted one focus group with the teachers in each setting and one focus group with the parents of children who had been actively involved in the project in each setting, resulting in four focus group transcripts in total. Interviews are a useful tool to help investigators research issues deeply; they offer opportunities for researchers to see how participants make connections between their 'ideas, values, events, opinions, behaviours' (Cohen, Manion, and Morrison 2017, 506). Focus group interviews, in particular, offer the opportunity to explore similarities and difference in world views. In the New Zealand context, the teachers and researchers also set up an exhibition of the children's artwork as a tool to facilitate the parents' recall of the project prior to the focus group. In China, the teachers met with the researcher and engaged in in-depth dialogue about their process which was audio recorded.

In each research context the researchers used an iterative coding process to identify themes in the documentation and in the focus group interviews and these were then shared across the two research contexts. The aim of the analytical process was to generate 'a coherent and compelling interpretation of the data, grounded in the data' (Braun et al. $2019,848)$, that could authentically capture the meaning-making occurring in each kindergarten context.

\section{Key findings}

Key findings that emerged from the data revealed that, overall, teachers and parents believed there were positive benefits from the use of storytelling as stimulus for teaching and learning. For instance, Awarua and the Dragon stimulated teachers to offer many learning opportunities that could enhance children's understanding of the story. As well as regular storytelling, this included: visual art, book making, cooking, dramatic play, block construction, shadow puppets, loose parts construction, carpentry, dough, sand and water play. 
At Karehana Bay Kindergarten, for example, teachers began planning the project by considering what possible materials and experiences could be offered to the children as ways of exploring the ideas in the story in depth. To kick start the project, they communicated the story via email to the families during a term holiday break in order to encourage their involvement and make a learning connection between home and kindergarten. When the children returned to kindergarten, teachers read the story of Awarua and the Dragon to the children at mat times and investigated what the children had found out about the story at home.

The teachers then set up specific provocations in the art area in order to facilitate the children's expression of ideas (Figure 1). Art experiences about Awarua the taniwha became opportunities for rich dialogue between teachers and children. Ideas were debated, exchanged and developed which encouraged teachers to set up new opportunities for the children to create art. For example, the children were encouraged to collaborate by sharing ideas and skills to create giant murals. As they noticed the children bringing the story and character of Awarua into their play, the teachers often responded by offering further resources to encourage and extend this exploration. They also spent time alongside children entering into language-rich discussions, scaffolding skills, and being enthusiastic about the children's ideas (Figure 2).

Some parents reported that their children were teaching their families about Awarua and incorporating Awarua into their play and artwork at home. In the holiday break many families responded keenly to a prompt by the teachers to search for taniwha artwork in their local community (for instance, local sculptures, murals, or paintings).

The teachers often told the Awarua story when they took children out into the local natural environment. The children often spontaneously created ephemeral artworks about taniwha at the beach and in the bush, and acted out the story in these locations. Toward the end of the project, Ngāti Toa (the local Māori tribe), gifted the kindergarten a chant which told the story of the explorer Kupe arriving in the area and discovering

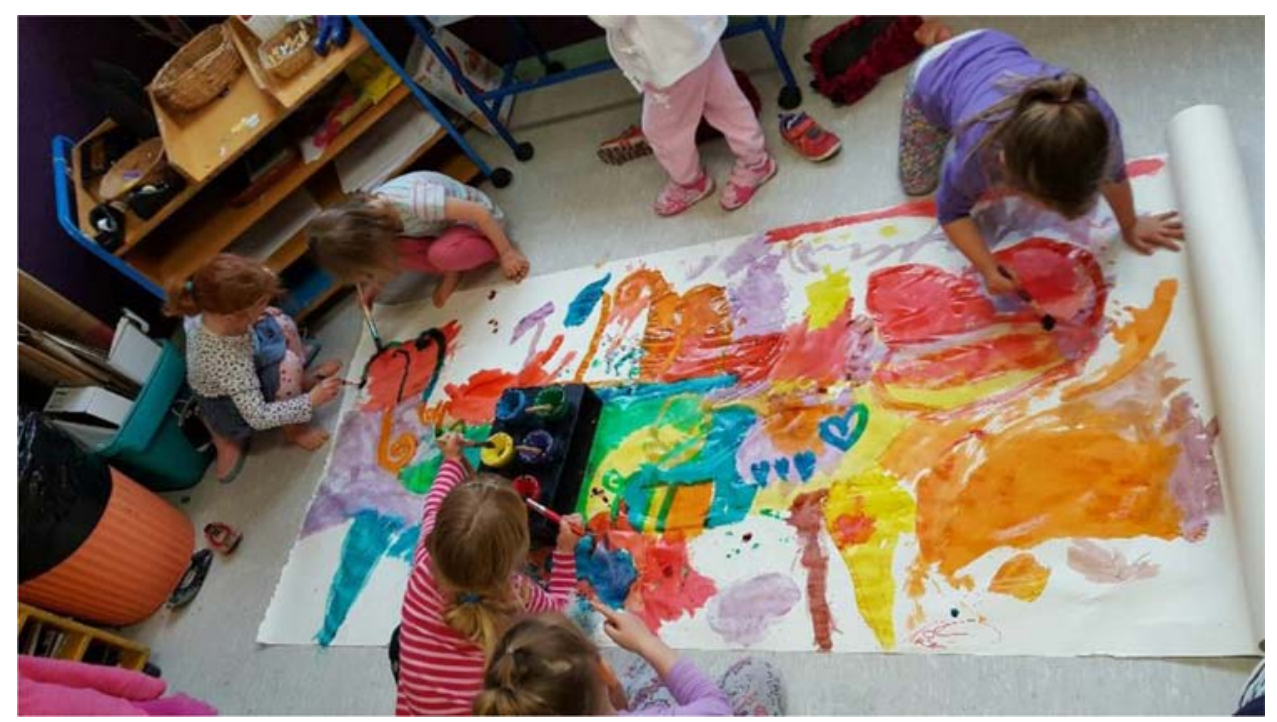

Figure 1. Collaborative mural making at Karehana Bay kindergarten. 


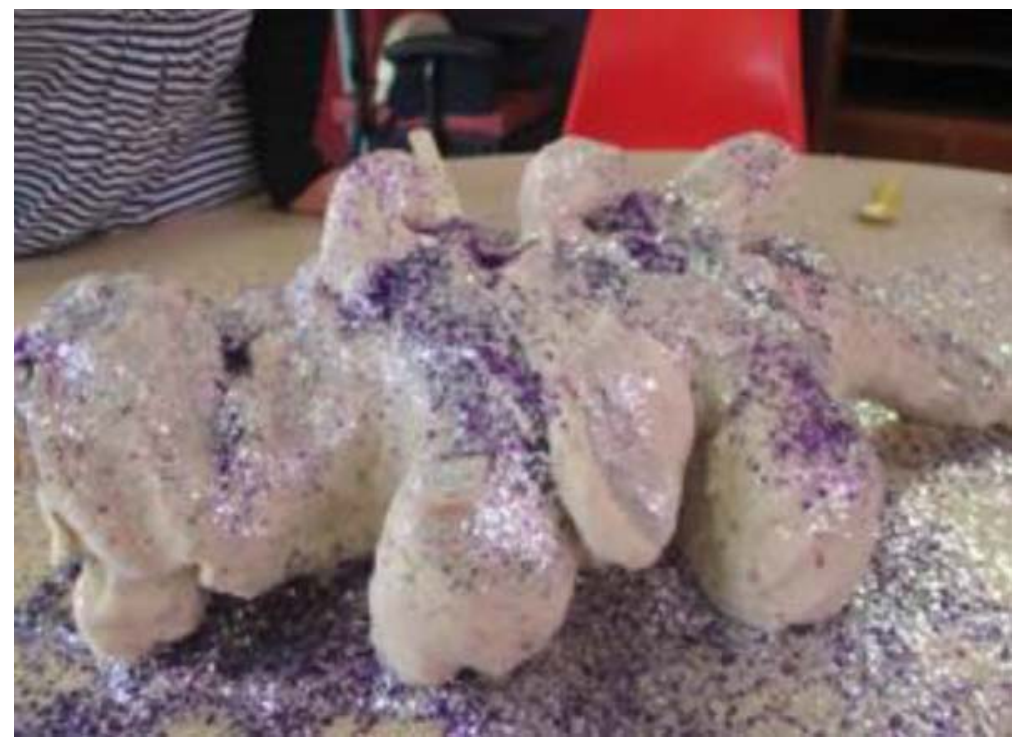

Figure 2. Awarua the playdough taniwha.

local landmarks including Mana Island, which is central to the Awarua story. This was a meaningful extension of the kindergarten community's developing connection to and understanding of local history and stories. The song became very special to the children, and was sung almost every day at group times.

The teachers at Lotus Kindergarten took some similar approaches across the six different classes involved. For instance, teachers in classes working with 4 to 6-yearold children used the story to introduce the project to the children and, like the teachers at Karehana Bay, they used it to see how the children responded. They collected children's thoughts and ideas about dragons to establish what they already knew. Actively listening to the children and encouraging dialogue helped teachers avoid being too teacher-directed. Through this they were delighted to discover how much children knew about dragons and how imaginative their working theories about these mythical creatures were. Like the Karehana Bay children, the Lotus children used many different forms of media to explore their ideas about dragons (Figure 3).

A different way to engage in the story was evident in another class where the teachers noticed that many of the children in that class were born in the Year of the Dragon or the Year of the Snake (the small dragon). Using this knowledge, the teachers asked the parents to write a story to the children about their birth, identifying where the child was born, and sharing the meaning of their names and their wishes for their child. The teachers put all the stories about the children together as a book and let the children read and retell their stories (Figure 4).

One of the classes discovered that initially children did not have many ideas about dragons, so the teachers provided some books about them. Through this the children developed a passionate interest in one particular book and often recreated this through role-play. 


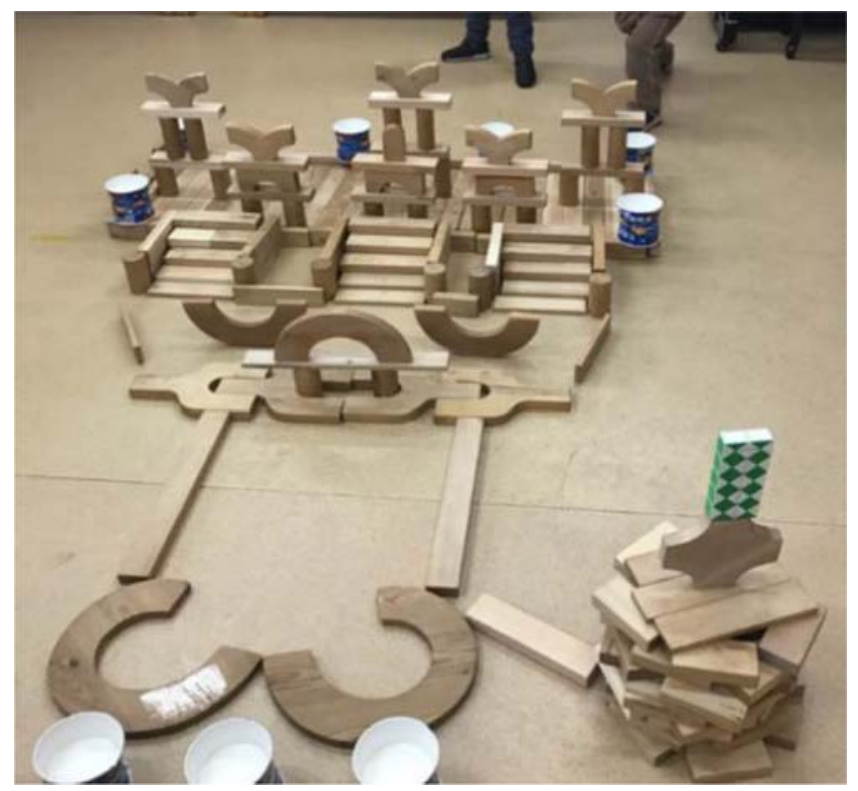

Figure 3. A block building by Sanyili children of the palace where the dragon lives.

In a number of the Lotus classes the teachers attempted to make connections for the children with the dragon by introducing particular food such Long Xu noodles (the dragon's whiskers) and Dragon Eye fruit. They also provided various dragon artefacts to examine (e.g. dragon shaped jade, a paper cutting with dragons, dragon kites, a dragon outfit), and talked with the children about the significance of the Dragon Boat festival. The project gave teachers a very legitimate reason to introduce and initiate opportunities for children and families to explore traditional stories and myths in new and exciting ways.

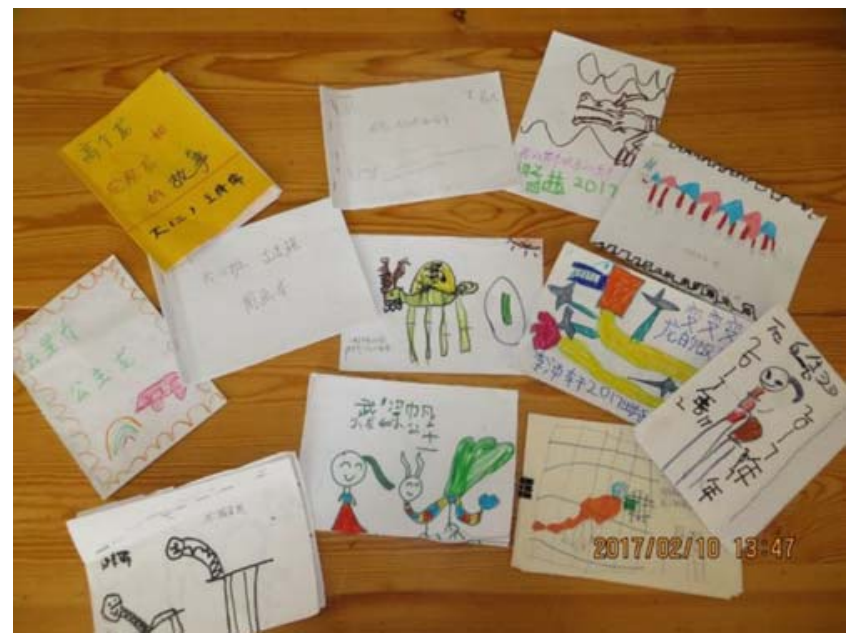

Figure 4. The Lotus children's paper cutting of dragons were made into books. 
The mythical creatures identified in the Awarua and the Dragon story became characters in the children's lived experience that were just as popular, if not more so, than characters from contemporary popular culture. In both contexts the story telling process helped the teachers to realise they could explore their own cultural resources more deeply, and to think about how to connect traditional cultural activities with kindergarten life. A good example of this was seen when Awarua became a significant figure in Karehana Bay kindergarten children's own culture and group identity and was often talked about at home. The children's engagement resulted in parents also getting excited by the investigation. For instance, one of the parents noted:

It's really exciting that she's kind of sharing that [story] with her big sister too ... the story telling side of it would come out a night time [she would say] 'I'm going to tell you a story!', and not from a book just from herself ... which was really lovely.

Another parent commented that she had grown up in Karehana Bay and gone to the kindergarten but never knew the local story of the taniwha and why Mana Island was flat. Another parent felt that the story had connected with their family's Welsh heritage due to the dragon appearing on the Welsh flag. Some of the parents also commented how the story, along with the regular kindergarten beach and bush walks, contributed to their children's sense of place and community.

Parents at Lotus Kindergarten also commented on the way that the children's learning about the dragon had also connected parents with their own cultural symbols and cultural knowledge. One parent, reflecting on the process for her son, commented that:

... through the activities the kindergarten had organised, it [traditional culture] became real and integrated to his life, and let him understand it slowly. I think that culture is always like the rain moistening the crops gently and silently, and goes into children's hearts slowly.

Parents from both kindergartens were appreciative of the way that the story had also given the opportunity for children to be exposed to knowledge and cultures of other parts of the world. As one Lotus parent noted:

Also, the teachers shared a story in the WeChat group. I found the foreign dragon is different to our Chinese dragon. Later, I bought some dragon book for my child, and I noticed that many foreign dragons looked different to our Chinese one. I wanted my child to know this too. Dragons all over the world are different.

A parent from Karehana Bay commented on the cultural exchange between the two kindergartens saying:

One day I came in and there was a skype session with China and that was amazing because the children were singing to each other in their own languages and it was such a beautiful connection.

An unanticipated finding from the research revealed that although teachers used a range of relevant teaching strategies throughout the project, teachers at both kindergartens expressed some concerns about being overly teacher-directive with the children as a result of introducing the story as a stimulus. Both kindergartens believed they practiced reciprocal and responsive, relationship-based pedagogies but, as could be expected when trying out new ideas, the project included some pedagogical knots for the teachers to unravel as it went along. 
The research showed that modelling, demonstrating skills, asking open-ended questions, facilitating discussions, engaging in shared thinking with children and each other, problem solving, and planning and documenting children's learning were important teaching strategies throughout the project. In some instances, teachers and parents very much enjoyed co-constructing artefacts with the children. Nonetheless, there were tensions for the teachers in both contexts about implementing a project that sometimes involved adult-initiated teaching or the provision of learning experiences that were determined by teachers (Figure 5).

\section{Discussion}

The findings that emerged from our data revealed that there were many positive benefits from the use of storytelling as a stimulus and two of the key benefits will be discussed more fully here. Using the story-telling helped children, teachers and families to learn about and become more aware of their own cultural heritage as well as the cultural heritage of the partner kindergarten through the provision of a range of learning experiences with different literacies which helped them to gain new knowledge. However, during the project teachers' existing ideas about what constituted good teaching practice were sometimes challenged. For example, to be (or not to be) more intentional and directive at times in their teaching.

\section{The importance of providing multi-literacy learning experiences for enhancing cultural knowledge}

The ways in which children in both kindergartens used materials and resources in response to Awarua and the Dragon illustrated the importance of providing children with a range of multi-literacy learning experiences to help them explore ideas in relation to characters in the story. It was clear that these experiences helped children gain new

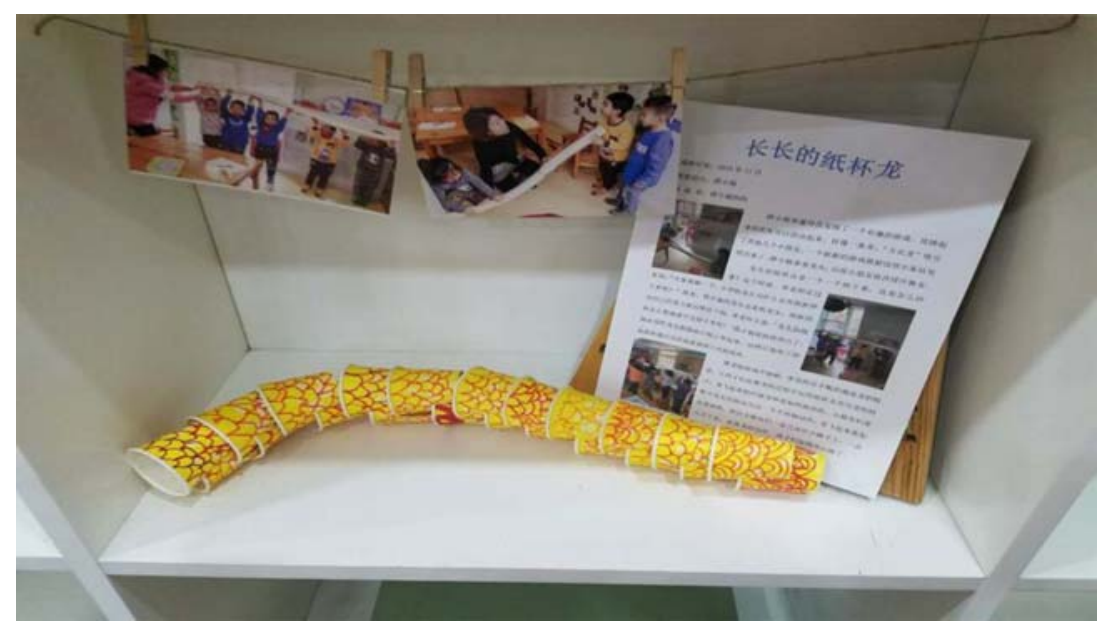

Figure 5. A Lotus kindergarten teacher and the children created a paper dragon together with paper cups. 
knowledge and working theories, helped them make their learning and thinking visible (Giudici, Rinaldi, and Krechevsky 2001), and transformed their understandings of their own sense of place and cultural identity. For instance, the Karehana Bay children developed a strong attachment to Awarua their local taniwha, and the Lotus kindergarten children thoroughly investigated the many dimensions of Chinese dragons.

Brooks (2005) research, which focusses on children's drawing, has implications for the children's multi-literacy explorations described in this project. Like Brooks, we found that drawing and other forms of creative expression using multi-literacies served 'as a vehicle[s] of exchange within the wider learning community' (90), where children were able to represent complex ideas through their creations, use multi-literacies to extend and transform their understanding and knowledge, and effectively communicate these ideas to their teachers and families.

The parents interviewed in our research appeared to become more aware of the richness of the multi-literacy experiences their children were having throughout the project. One of the Karehana Bay parents illustrated this clearly when she recognised that the project had enabled her child to transform her understandings about their local taniwha on a daily basis, as well as help develop her drawing skills and imaginative representations. She stated,

What she [my child] mostly liked was the painting and the groupness, and being able to do it with everyone ... for the whole 2 weeks she was just doing taniwha every single day she came to kindy. We got a book of them! And they seemed to change every day.

A parent from Lotus kindergarten also reflected on how the range of multi-literacies her child was engaged with 'opened a door to him' through fostering opportunities for new explorations and learning. Another parent commented on the power of the approach which allowed many different ways to explore the topic. She had initially thought the idea of using the dragon for children's learning was quite abstract but, instead, she found that:

In fact, they (teachers) used a lot of ways, including using children's visual sense, hearing and taste to help them explore. There was a group of children watching the teacher cooking Long Xu noodles. Long Xu was the dragon's whisker. This is a symbol of the dragon, so I think they use this more vivid way to understand such an abstract thing.

Our research has shown that for both kindergartens the story Awarua and the Dragon provided the impetus for teachers to provide learning experiences that supported children's exploration of some of the important stories and symbols of both nations (Ministry of Education 2017; Ministry of Education of People's Republic of China 2012). We feel that this type of exploration, and the resulting understandings and knowledge, can help play an important part in keeping cultures alive (UNESCO 2011; Smith 2010). Aspects of culture that are manifested in the ' $\ldots$ traditions or living expressions inherited from our ancestors and passed on to our descendants, such as oral traditions, performing arts, social practices, rituals, festive events ...' (UNESCO https://ich.unesco. org/en/oral-traditions-and-expressions-00053, para 1), are clearly an important part of young children's learning. In New Zealand, pūrākau (myths and legends) and other cultural stories are considered important for preserving ancestral knowledge and are a significant feature of Māori culture. For instance, Lee believes pūrākau are not 'mere tales' but often reflect a Māori worldview and portray 'the lives of our tupuna (ancestors) in 
creative, diverse and engaging ways' $(2005,2)$. The New Zealand early childhood curriculum Te Whäriki (Ministry of Education 2017, 42), encourages teaches to embrace 'stories and literature valued by the cultures represented in the community'.

The Karehana Bay kindergarten teachers were very cognisant of this aspiration of the curriculum. One of their strategic planning goals at the time of the project was for the teachers (and children) to ensure that Māori language and stories were highlighted in the curriculum, to honour the Treaty of Waitangi (New Zealand's founding document) and to educate children about the indigenous people of the local area by increasing their own familiarity with local Māori legends. This research highlighted that through facilitating learning experiences for children that stemmed from the storytelling (such as the creation of a collaborative mural painting of Awarua) and learning a song about Kupe the famous Māori explorer, teachers and parents as well as the children gained more knowledge about aspects of Māori culture and places of symbolic significance in their local area.

In China, one of the important goals for undertaking the Awarua and the dragon project was to enable the Lotus kindergarten teachers to reconnect with aspects of Chinese culture in line with current government education policy. Chinese educational commentators and academics Zhu and Zhang (2018) suggest that 'our curriculum reform should reflect on our own culture's merit and try and preserve it ...' (1182). President Xi Jinping has emphasised the importance of assisting Chinese people to strengthen their confidence in their own culture and develop cultural confidence. Increasingly, Chinese kindergartens have started to explore ways of integrating cultural topics and activities into their programmes and many of the Lotuis teachers used the Awarua and the Dragon to investigate the mythical aspects of Chinese dragons with the children through multi-literacy opportunities. It also provided a springboard into investigating other significant Chinese legends.

\section{Intentional teaching and other pedagogical knots}

A recurring teaching strategy identified in this research was the place of intentional teaching. McLaughlin, Aspden, and Snyder (2016) define this as a teaching approach that involves 'the purposeful and deliberate actions of teachers, drawing on both their knowledge of individual children and professional knowledge to provide meaningful and appropriate curricular experiences for all children in ECE' (176) and 'the use of planned and purposeful actions to organise learning experiences for children' (182). However, Leggett and Ford (2013) argue that it is important to acknowledge the current context of predominantly play-based and child-centred curriculum in many countries when discussing the concept of intentional teaching. In this research, a tension emerged for the teachers between the power of the teacher and the power of the child in an intentional teaching approach to curriculum design. The tension in the project provided a rich opportunity for discussions about appropriate pedagogy and practice in their context. The teachers came to recognise that 'the role of the intentional teacher requires careful consideration, balancing an intentional curriculum that acknowledges the rights of children's active participation within the teaching/learning nexus' (Leggett and Ford 2013, 42). Our findings revealed that the teachers in China and New Zealand were able to explore the subtle complexities of intentional teaching 
and through the project were able to move away from a dichotomy between teacherdirected and child-led approaches in ECE.

Previous research in Chinese kindergartens has shown that teachers tended to pay more attention to teacher-directed teaching (Zhang and Xiang 2016; Wu 2017) and that this has often occurred through theme-based teaching. However, there have been some pedagogical shifts towards child-centred learning in recent years (Zhou 2013) and consequently, at Lotus kindergarten, teachers firmly believed that it was important to listen to children's ideas and gather their working theories and to let the children lead the learning process and be the drivers of curriculum.

The provision of a richly resourced environment and the engagement of parents is seen by Lotus teachers as important for enacting a pedagogical approach that emphasises noticing, recognising and responding to children's learning interests. Nonetheless, tensions arose from a fear of slipping back to old habits of teacher-directed thematic projects. One teacher commented 'At the beginning I was afraid that this project would be like the theme-based activities'.

For the teachers of Lotus Kindergarten the project created the challenge of having specific intentions for learning, such as exploring ideas and concepts relating to taniwha and dragons, as well as exploring cultural and national symbols of identity. They needed to be reassured that listening to children's ideas and working theories about dragons and China would be an important dimension of the project.

However, during the project, teachers' existing ideas about what constituted good teaching practice were sometimes challenged. For example, to be (or not to be) more directive at times in their teaching. This became a pedagogical knot for the Lotus teachers to unravel. However, by allowing uncertainty and flexibility during the process, having facilitated pedagogical discussions and having the necessary resources and professional learning opportunities helped the teachers to overcome their anxieties about this strategy.

Another pedagogical knot for the Lotus Kindergarten was around whether teachers felt they had enough of their own personal knowledge to support the children's investigations. One teacher stated she was worried 'because teachers do not have in depth understanding of our own culture, [I] do not have enough knowledge and understanding of dragon myself, so may inhibit the children's learning to a certain degree'. However, this concern was addressed as the project progressed because the teachers found that by exploring the idea of the dragon alongside the children (for example, by reading books and even attending a lecture discussing the relationship of dragon to Chinese culture), their awareness of their own identity and their understanding of the significance of cultural symbols, such as dragons, expanded.

Like the Chinese teachers, the Karehana Bay teachers shared a fear of limiting children's learning by teacher's having too much control of the process and directing learning. One teacher commented that other ECE teachers might be too scared to try a project like this because of the fear that 'you can't tell children what to do'. However, the teachers agreed that the project was not about telling the children what to do, but about offering new opportunities and ideas that could take them in new directions if they wanted.

A very specific knot occurred for the Karehana Bay teachers when they set up provocations in the art area to help facilitate the children to express their ideas about the story 
through visual arts learning experiences. In one instance, this involved intentionally providing the children with printed images of taniwha (accessed from books and the internet) to provoke their thinking and generate ideas for their own work. The Head teacher said:

I think investigating something that is imaginary is quite tricky so we gave them a range of ways different people represent taniwha, so that they could look through lots of different drawings [using images of] some children's art work and some adults art work of taniwha.

Because these teachers seldom gave children direct examples to use for their drawing, they had some concerns about restricting children's creativity by providing a model to 'copy'.

However, this particular knot was unravelled when it became apparent that the printed images actually were a springboard for the children's own imaginative and creative representations. The teachers saw that this strategy empowered the children to develop their confidence in representing their ideas. The Head teacher explained the resulting artwork became 'something they were really proud of and they knew that it was so valued, so they would always feel so proud whenever they had Awarua in their art work'.

Intentional teaching clearly played a useful and important component in both kindergarten contexts, despite the teachers having some anxieties about it being construed as providing theme-based explorations or teacher, directed activities. They enacted Thomas, Warren, and deVries's (2011) suggestion that, 'to move beyond such a binary requires the consideration of play-based pedagogy and intentional teaching as elements of a professional philosophy that can be held together because both are necessary to support children's learning' (74). Nonetheless, the teachers in this project discovered ways to make thoughtful and purposeful decisions about what to offer children to enrich and extend learning, while still seeing children as competent, active and empowered.

\section{Limitations and trustworthiness of the study, and possibilities for teacher practice and research}

This was a small-scale study involving two ECE settings in two countries chosen because of established professional relationships, and does not aim to represent the sector in either country. The main data was generated through interviews with groups of parents and groups of teachers, and learning assessment documentation (for example, photos, Learning Stories, notes, journals). Interviews with children were beyond the technical and ethical scope of this study.

In spite of this, aspects of the study design engender a sound sense of trustworthiness. The research was co-designed between university researchers and the teachers and data was triangulated between teachers' interviews, parents' interviews and documentation. The collaborative iterative coding process involving all four researchers was developed to ensure reliability of analysis. Furthermore, findings were member-checked with the teacher participants who indicated that they resonated with their experiences of the project. 
The findings of this study has lead us to develop some practical suggestions for ECE teacher practice. ECE teachers can enhance children's learning by:

- Using traditional and imagined stories as a stimulus for the development of cultural identity and appreciation of other cultures.

- Using stories as a curriculum springboard for rich and varied learning through the provision of a wide range of multiliteracies.

- Practicing intentional teaching strategies that enrich children's learning by going beyond the limitations of strictly following children's interests. These include: demonstrating, modelling, questioning, scaffolding, planning, extending and engaging in meaningful dialogue with children about their ideas.

We suggest that future research possibilities to build on this study could involve implementing a similar curriculum connection between two new settings, with more of an emphasis on collaboration and shared professional learning between the two teaching teams. Gathering data directly from children by recording conversations would also be a fruitful avenue to explore.

\section{Conclusion}

Our data revealed that throughout the Awarua and the Dragon project New Zealand and Chinese children used a range of multi-literacies to express their ideas and make their thinking visible. This supports Haggerty and Mitchel's (2010) research which led them to fervently believe that there is a great 'need for early years teachers to take a broad view of literacies as modes of communication, conceptualisation and meaning-making, so that children's favoured modes can be noticed, supported and expanded' (338). Our research supports these sentiments and highlights how important different forms of communication are for assisting children to expand their skills, knowledge and, in the words of a teacher from Lotus Kindergarten, their 'beautiful imaginations'.

Throughout the story-telling project the teachers in New Zealand and in China intentionally introduced ideas for increasing children's knowledge and learning through the provision of rich experiences and, at the same time, empowered children to follow their own ideas and lead their own learning. However, the educational, historical and cultural contexts of both kindergartens meant that the learning journeys of the two teaching teams were interspersed with different kinds of questions and provocations about the teaching and learning involved in this work. McArdel, Grieshaber, and Sumison (2019) suggest that combining play-based learning with intentional teaching requires careful consideration as it can involve very nuanced pedagogical approaches. This was clearly evident in this project.

Connecting children, teachers and families with significant aspects of their own and others' cultures, were important outcomes of the project. The use of a story as a provocation in this project demonstrates that 'an understanding of the intangible cultural heritage of different communities helps with intercultural dialogue, and encourages mutual respect for other ways of life' (UNESCO 2011, 4). As a result of this project we strongly believe that the use of a story telling stimulus, like Awarua and the Dragon, can be a 
powerful tool for supporting teaching and affording diverse pathways of teaching and learning.

\section{Disclosure statement}

No potential conflict of interest was reported by the author(s).

\section{ORCID}

Rachel Denee (i) http://orcid.org/0000-0002-9508-6083

Jing Zhou (D) http://orcid.org/0000-0003-2171-1680

\section{References}

Bagnoli, A. 2009. "Beyond the Standard Interview: The Use of Graphic Elicitation and Arts-Based Methods.” Qualitative Research 9 (5): 547-570.

Black, S. 1999. "Using Polynesian Legends and Folktales to Encourage Culture Vision and Creativity." Childhood Education 75 (6): 332-336.

Braun, V., V. Clarke, N. Hayfield, and G. Terry. 2019. "Thematic Analysis.” In Handbook of Research Methods in Health Social Sciences, edited by P. Liamputtong, 843-860. Singapore: Springer Singapore.

Brooks, M. 2005. "Drawing as a Unique Mental Development Tool for Young Children: Interpersonal and Intrapersonal Dialogues." Contemporary Issues in Early Childhood 6 (1): 80-91.

Carr, M., and W. Lee. 2012. "Learning Stories: Constructing Learner Identity in the Early Years". London: Sage.

Cohen, L., L. Manion, and K. Morrison. 2017. Research Methods in Education. New York: Routledge.

Edwards, S., and A. Cutter-Mackenzie. 2011. "Environmentalising Early Childhood Education Curriculum Through Pedagogies of Play." Australasian Journal of Early Childhood 36 (1): 51-59.

Giudici, C., C. Rinaldi, and M. Krechevsky. 2001. Making Learning Visible: Children as Individual and Group Learners. Project Zero. Cambridge: Harvard Graduate School of Education.

Haggerty, M., and L. Mitchel. 2010. "Exploring Curriculum Implications of Multimodal Literacy in a New Zealand Early Childhood Setting." European Early Childhood Education Research Journal 18 (3): 327-339.

Henning, K., and A. Kirova. 2012. "The Role of Cultural Artefacts in Play as Tools to Mediate Learning." Contemporary Issues in Early Childhood 13 (3): 226-241.

Kelly-Ware, K., and N. Daly. 2019. "Using Picturebook Illustrations to Help Young Children Understand Diversity." International Art in Early Childhood Research Journal 1 (1): 1-11.

Lee, J. 2005. "Māori Cultural Regeneration: Pūrākau as Pedagogy." Paper Presented as Part of a Symposium Indigenous (Māori) Pedagogies: Towards Community and Cultural Regeneration. Centre for Research in Lifelong Learning International Conference, Stirling, Scotland. http:// citeseerx.ist.psu.edu/viewdoc/download?doi=10.1.1.580.4626\&rep=rep1\&type=pdf.

Leggett, N., and M. Ford. 2013. "A Fine Balance: Understanding the Roles Educations and Children Play as Intentional Teachers and Intentional Learners Within the 'Early Years Learning Framework'.” Australasian Journal of Early Childhood 38 (4): 42-50.

Liu, Y., and Y.-J. Pan. 2013. "A Review and Analysis of the Current Policy on Early Childhood Education in Mainland China.” International Journal of Early Years Education 21 (2-3): 141151.

May, H. 1997. The Discovery of Early Childhood. Wellington: NZCER.

McArdel, F., S. Grieshaber, and J. Sumison. 2019. "Play Meets Early Childhood Teacher Education." The Australian Educational Researcher 46: 155-175. 
McLaughlin, T., K. Aspden, and P. Snyder. 2016. "Intentional Teaching as a Pathway to Equity in Early Childhood Education: Participation, Quality, and Equity.” New Zealand Journal of Educational Studies 51 (2): 175-195.

Ministry of Education. 2017. "Te Whāriki: He Whāriki Mātauranga Mō Ngā Mokopuna o Aotearoa: Early Childhood Curriculum". Wellington: Ministry of Education.

Ministry of Education of People's Republic of China. 2012. "Early Learning and Development Guidelines for Children Aged 3 to 6 Years".

Murray, J. 2015. "Early Childhood Pedagogies: Creating Spaces for Young Children to Flourish.” Early Child Development and Care 185 (11-12): 1715-1732.

The New London Group. 1996. "A Pedagogy of Multiliteracies: Designing Social Futures." Harvard Educational Review 66 (1): 60-92.

Penitito, W. 2009. "Place-Based Education: Catering for Curriculum, Culture and Community." New Zealand Annual Review of Education 18 (5): 5-29.

Peters, S. 2009. "Responsive, Reciprocal Relationships: The Heart of the Te Whāriki Curriculum Chap. 2.” In Learning Together in the Early Years: Exploring Relational Pedagogy, edited by T. Papatheodorou and J. Moyles, 23-32. New York: Routledge.

Robins, J. 2005. "Contexts, Collaboration, and Cultural Tools: A Sociocultural Perspective on Researching Children's Thinking." Contemporary Issues in Early Childhood 6 (2): 140-149.

Rogoff, B. 2003. "The Cultural Nature of Human Development". New York: Oxford University Press.

Smith, J. 2010. "Biculturalism and Multiculturalism: Competing Tensions in Visual Arts Education in Aotearoa-New Zealand." International Journal of Multicultural Education 12 (2): $1-18$.

Stetsenko, A. 2005. "Activity as Object-Related: Resolving the Dichotomy of Individual and Collective Planes of Activity." Mind, Culture, and Activity 12 (1): 70-88.

Terreni, L. 2016. "Awarua and the Dragon”. http://olivepress.co.nz/Awarua_and_the_dragon. html.

Terreni, L., J. Loveridge, R. Denee, and J. Zhou. 2018. “Awarua and the Dragon: Enhancing Young Children's, Teachers and Parents' Sense of Place and Cultural Identity Through Art and Storytelling." International Art in Early Childhood Research Journal 1 (1): 1-11.

Thomas, L., E. Warren, and E. deVries. 2011. "Play-Based Learning and Intentional Teaching in Early Childhood Contexts.” Australasian Journal of Early Childhood 36 (4): 69-75.

Tobin, J., Y. Hsueh, and M. Karasawa. 2009. Preschool in Three Cultures Revisited. Chicago: The University of Chicago Press.

UNESCO. 2011. "What is Tangible Cultural Heritage?” https://ich.unesco.org/doc/src/01851-EN. pdf.

White, J., F. Ellis, A. O’Malley, J. Rockel, S. Stover, and M. Toso. 2008. "Play and Learning in Aotearoa New Zealand Early Childhood Education. Chap. 2." In Play and Learning in Early Childhood Settings: International Perspectives, edited by I. Pramling Samuelsson and M. Fleer, 19-49. Dordrecht: Springer.

Wu, N. 2017. "Zhongguo Chuantong Youxiu Wenhua Zai Youeryuan Xuqu HuodongZhong de Yunyong [The application of excellent Chinese traditional culture in the kindergarten regional activity]" (Unpublished master's thesis). Shangdong Normal University, China.

Yin, R. 2018. Case Study Research and Applications: Design and Methods. London: Sage.

Zhang, A., and Y. Xiang. 2016. "Youer Zhonghua Youxiu Chuantong Wenhua Jaaoyu de Shijian Lujing. [Research on the Practice Path of Children's Excellent Traditional Culture Education]." Jiaoyu Cankao 2: 76-79.

Zhou, J. 2013. "Living With Tensions: Chinese Early Childhood Teachers' Teaching and Learning Experiences in Contemporary Urban Chinese Context". Unpublished PhD Thesis. Victoria University of Wellington.

Zhu, J., and J. Zhang. 2018. "Review and Reflection on the Curriculum Reform of Early Childhood Education in China. Chap. 60.” In International Handbook of Early Childhood Education, edited by M. Fleer and B. van Oers, 1173-1190. Dordrecht: Springer International Handbooks of Education. 